ORIGINAL ARTICLE

\title{
Managing partners of people diagnosed with Chlamydia trachomatis: a comparison of two partner testing methods
}

\author{
L Østergaard, B Andersen, J K Møller, F Olesen, A-M Worm
}

Sex Transm Infect 2003;79:358-362

See end of article for authors' affiliations

Correspondence to:

$\operatorname{Dr} L$ Østergaard, Research

Unit Q, Department of

Infectious Diseases, Skejby

Sygehus, Aarhus

University Hospital, DK-

8200 Aarhus N, Denmark;

oes@sks.aaa.dk

Accepted for publication 26 June 2003

\begin{abstract}
Objective: To compare the effectiveness of "home sampling" with that of "office sampling" for testing partners to men and women infected with Chlamydia trachomatis.

Method: A randomised controlled effectiveness trial took place in the general community in Denmark. 1300 index women and 526 index men ( $\geqslant 18$ years) with a positive test result for $C$ trachomatis were identified. Of these, 414 index women and 148 index men gave implied consent. Index patients were randomly assigned to provide their partner(s) through the past 12 months with either (1) a kit by which partner(s) could be tested by home sampling, or (2) a kit by which partner(s) could only be tested by seeing a healthcare professional (office sampling). The main outcome measure was the proportion of index patients who had at least one partner tested for $C$ trachomatis.

Results: The proportion of index women with at least one partner tested was higher in the home sampling group (0.26) than in the office group (0.12) (difference $0.14 ; 95 \% \mathrm{Cl} 0.10$ to $0.19 ; \mathrm{p}<0.0001$ ) and so it was for index men $(0.15 \vee 0.03$; difference $0.12 ; 95 \% \mathrm{Cl} 0.07$ to $0.16 ; p<0.0001)$. Also the proportion of index women for whom at least one partner was identified as infected was higher in the home sampling group compared with the office group $(0.11 \vee 0.07, p=0.01)$. The corresponding figures for index men were $0.06 \vee 0.01, p=0.02$.

Conclusion: The effectiveness of partner testing is higher when partners of $C$ trachomatis infected patients are offered home sampling than when they are offered office sampling.
\end{abstract}

opulation based surveys have found urogenital Chlamydia trachomatis infection rates between $3 \%$ and $6 \%$ in young men and women, ${ }^{1-4}$ and a substantial proportion of infected men and women do not have any symptoms or signs of disease. ${ }^{25} \mathrm{C}$ trachomatis infection may cause serious complications such as pelvic inflammatory disease (PID) ${ }^{3}$ which may result in chronic abdominal pain, female infertility, or ectopic pregnancy. ${ }^{6}$ However, if identified, the infection can be easily and effectively treated ${ }^{7}$ and complications in terms of PID avoided. ${ }^{8}$

Partner notification followed by prompt laboratory testing and treatment of exposed partners provides an excellent opportunity to decrease the duration of infectiousness and interrupt disease transmission. ${ }^{10}$ It is known, however, that the success of partner notification for $C$ trachomatis infections is far from optimal. Published data vary between 0.11 and 0.89 notified partners per infected patient. ${ }^{11-13}$ In these studies notified partners were offered testing with an invasive swab sample obtained by a healthcare provider in an office. Nucleic acid amplification tests allows self sampling. ${ }^{14}$ Furthermore, we have found an equal diagnostic efficacy $^{15}$ and higher clinical efficacy ${ }^{916}{ }^{17}$ of a strategy in which samples are taken in the privacy of home and mailed directly to a diagnostic laboratory by the patient (home sampling) compared with swab sampling in a medical office.

In this study we compare the effectiveness of offering partners home sampling instead of testing in a medical office (office sampling).

\section{METHODS}

\section{Study design}

The study was a randomised, double blind, controlled, parallel group study conducted in four counties in Denmark between February 1999 and March 2000. In order to compare the effectiveness of the two partner testing strategies rather

\section{Key messages}

- A partner testing strategy based on home sampling shows a twofold to fourfold higher effectiveness than a partner testing strategy based on samples obtained in a medical office

- The improved effectiveness of home sampling was relatively more pronounced for index men compared with index women

- A strategy of offering partners the opportunity of home sampling might contribute to improved public health control of the Chlamydia trachomatis infection

than the efficacy of these, we randomised the index patients based on a positive swab sample for $C$ trachomatis in the routine laboratory. Individuals with a positive test result were thus randomised to give their partners the opportunity of "home sampling" or to give their partners the opportunity of "office sampling."

\section{Recruitment of index patients}

Whenever a swab sample was found to be positive for $C$ trachomatis in the routine laboratory, the patient's identification was forwarded to the main study centre and the randomisation was done without prior consent. Through the healthcare provider, who requested the initial test, the index patient received a cover letter with explanation of the study and its purpose. In this letter information was given that if the index patient chose to submit the questionnaire he/she was considered enrolled in the study (implied consent). The study was approved by the Danish ethics committee system. 


\section{Package to the index patients}

The package to the index patients was mailed to his/her home address based on information provided by the healthcare provider. The package consisted of five specimen collection kits to be used by his/her sexual partners over the previous 12 months. This time period was decided based on advice from several European experts. The specimen collection kits for the two study groups were identical and the content of the specimen collection kit was thus blinded to the index patient.

The index patient was instructed to give the specimen collection kits to the partner(s) or mail them (post paid). In case the index patient chose not to forward the partner kits (dropout) they were asked to give the reason for this.

\section{Specimen collection kits for partners}

After receiving the specimen collection kits, partners in the home sampling group should mail their home obtained samples directly to the diagnostic laboratory in post paid and preaddressed envelopes. Partners in the office sampling group had to bring the specimen collection kit into the office of a healthcare provider to obtain a sample (office sampling). Partners in this group also brought a letter explaining the study and the importance that the health care provider used the provided specimen collection kit.

\section{Content of partner kits}

For male partners in the home sampling group the kit contained a $10 \mathrm{ml}$ tube for a first void urine sample and for female partners the kit consisted of a vaginal pipette containing $5 \mathrm{ml}$ sterile normal saline. ${ }^{2}{ }^{15} 16$ Women introduced the tip of the pipette $3 \mathrm{~cm}$ into the vagina and flushed and aspirated the saline. We previously found a high patient acceptability of this vaginal pipette. ${ }^{18}$

For the "office sampling" group the preaddressed envelope was replaced by a request to bring the specimen collection kit to a health care provider for testing. The healthcare provider then subsequently mailed the sample to the study centre.

\section{Testing for $C$ trachomatis}

The initial swab sample, on which the identification of possible index patients was obtained, was analysed by the LCx Chlamydia trachomatis test (Abbott, Chicago, IL, USA). This also held for vaginal flush samples and urine samples and both home obtained and office obtained samples.

Follow up and treatment of the $\boldsymbol{C}$ trachomatis infection All partners had their test result sent back to their own address or their physician's address depending on their marked preference. If the test was positive, the patient was requested to seek a healthcare provider for treatment.

\section{Study end point}

The primary end point of the study was the proportion of index patients with at least one partner tested for $C$ trachomatis. A secondary end point was the proportion of index patients with at least one partner having a $C$ trachomatis infection diagnosed.

\section{Definition of study populations \\ "Intention to test" population}

This consisted of all patients who had a positive test for $C$ trachomatis identified.

Included patients

The group of the "intention to test" population who accepted to receive information about the study.

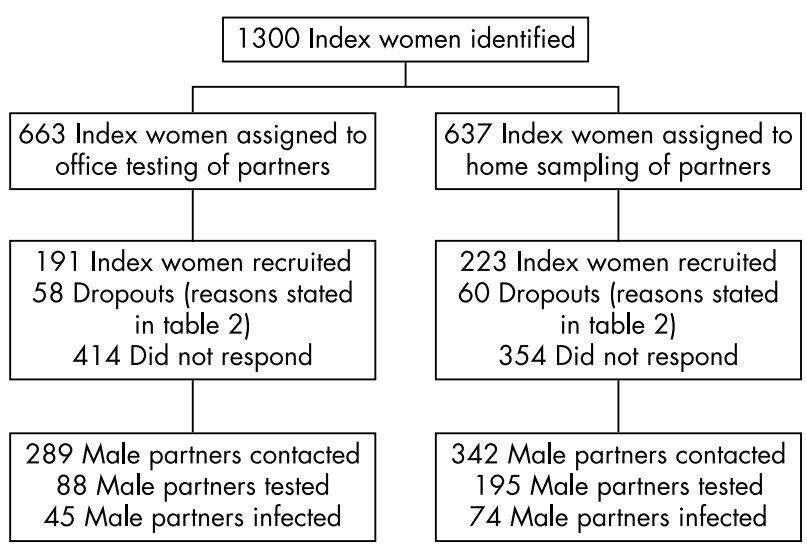

Figure 1 Flow chart for index women and their tested partners.

\section{Recruited patients}

The subgroup of included patients who agreed to contact their partners.

\section{Statistical analysis}

The primary analysis was performed according to the intention to treat principle and since the point of randomisation was the index patient, analyses were performed on index patients and not partners.

Partner testing rates were also calculated based on the "recruited patients" population.

Power calculations ${ }^{19}$ were based on a previous pilot study performed in Aarhus County. ${ }^{17}$

\section{RESULTS}

\section{Index women}

A total of 1300 C trachomatis infected women were identified. A chart of patient flow is shown in figure 1. To compare the characteristics between the two groups of patients who actually participated (the recruited patients), key features such as previous sexually transmitted infections, symptomatology, and sexual behaviour were collected. The characteristics of the $191(28.8 \%$; 191 of 663$)$ recruited index women in the office group were similar to the characteristics of the $223(35.0 \% ; 223$ of 637$)$ recruited index women in the home sampling group (table 1).

\section{Index men}

A total of 526 C trachomatis infected men were identified (fig 2). A chart of patient flow is shown in figure 2. The characteristics of the $67(24.9 \% ; 67$ of 269$)$ recruited index

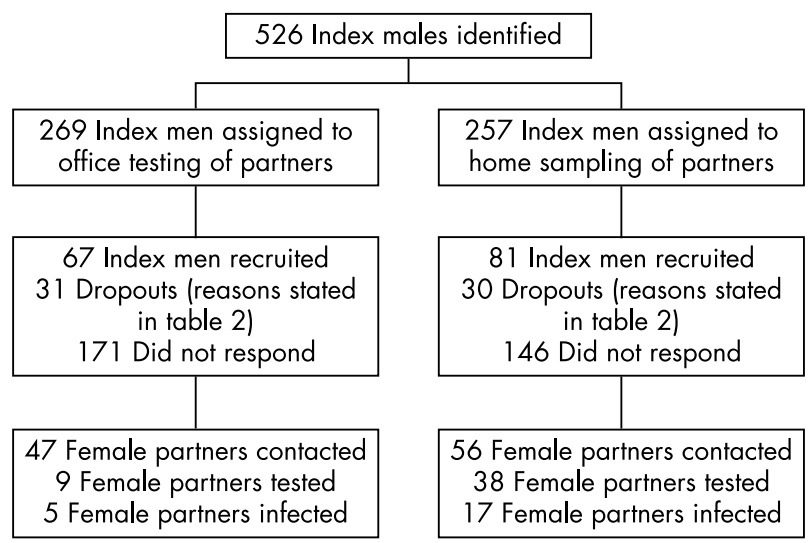

Figure 2 Flow chart for index men and their tested partners. 
Table 1 Demographic and behavioural data for participating index patients in the office sampling and home sampling groups

\begin{tabular}{|c|c|c|c|c|c|c|c|c|c|c|}
\hline \multirow[b]{3}{*}{ Characteristics } & \multicolumn{5}{|c|}{ Index women } & \multicolumn{5}{|l|}{ Index men } \\
\hline & \multicolumn{2}{|c|}{ Office sampling } & \multicolumn{2}{|c|}{ Home sampling } & \multirow[b]{2}{*}{ p Value } & \multicolumn{2}{|c|}{ Office sampling } & \multicolumn{2}{|c|}{ Home sampling } & \multirow[b]{2}{*}{ p Value } \\
\hline & No & $\%$ & No & $\%$ & & No & $\%$ & No & $\%$ & \\
\hline Recruited patients & 191 & & 223 & & & 67 & & 81 & & \\
\hline Age (SD) & $23.7(5.7)$ & - & $22.7(4.3)$ & - & 0.25 & $25.1(5.24)$ & - & $25.6(6.4)$ & - & 0.23 \\
\hline Age at first sexual intercourse (SD) & $16.4(2.2)$ & - & $16.0(2.1)$ & - & 0.33 & $16.4(2.2)$ & - & $16.4(1.9)$ & - & 0.85 \\
\hline White & 191 & 100 & 223 & 100 & - & 67 & 100 & 81 & 100 & - \\
\hline Previous $C$ trachomatis infection & 42 & 22.0 & 41 & 18.4 & 0.43 & 13 & 19.4 & 17 & 21.0 & 0.97 \\
\hline Previous other STD & 39 & 20.4 & 35 & 15.7 & 0.26 & 10 & 14.9 & 8 & 9.9 & 0.49 \\
\hline Current urogenital symptom(s) & 105 & 55.0 & 111 & 49.8 & 0.34 & 41 & 61.2 & 50 & 61.7 & 0.92 \\
\hline Current regular intimate relationship & 128 & 67.0 & 147 & 65.9 & 0.90 & 37 & 55.2 & 47 & 58.0 & 0.86 \\
\hline $\begin{array}{l}\text { Use of condom during the most recent } \\
\text { intercourse }\end{array}$ & 47 & 24.6 & 44 & 19.7 & 0.28 & 18 & 26.9 & 21 & 25.9 & 0.95 \\
\hline $\begin{array}{l}\text { Mean number of intimate relationships } \\
\text { during the past } 12 \text { months }\end{array}$ & 2.7 & & 3.0 & & 0.86 & 3.1 & & 3.1 & & 0.94 \\
\hline
\end{tabular}

men in the office group were similar to the characteristics of the $81(31.5 \%$; 81 of 257$)$ recruited index men in the home sampling group (table 1).

\section{Reasons for withdrawals (dropout)}

The major reported reason for index patients dropping out of the study was that his/her partner(s) were already aware of having a $C$ trachomatis infection. This reason was stated by $30.5 \%$ of the index women and by $32.8 \%$ of the index men (table 2).

\section{Effectiveness of testing male partners to infected index women}

The proportion of index women with one or more partner tested was $26.1 \%$ in the home sampling group and $11.8 \%$ in the office group $(\mathrm{p}<0.001)$ (table 3$)$. The relative effectiveness of offering home sampling to male partners compared with office sampling was thus $2.2(26.1 \% / 11.8 \%)(95 \% \mathrm{CI}$ : 1.7 to 2.8 ). The proportion of all index women with at least one partner identified as infected with $C$ trachomatis was $10.8 \%$ in the home sampling group and $6.6 \%$ in the office group $(\mathrm{p}=0.01)$, a relative effectiveness of $1.63(10.8 \% / 6 . \%)$ (95\% CI: 1.1 to 2.3$)$.

\section{Effectiveness of testing female partners to infected index men}

Among randomised index men, the proportion with one or more partners tested was $14.8 \%$ in the home sampling group and $3.3 \%$ in the office group $(\mathrm{p}<0.001)$ (table 3$)$. The relative effectiveness of offering home sampling to female partners compared to office sampling was thus 4.4 (14.8\%/3.3\%) $(95 \%$ CI: 2.2 to 9.0 ). The proportion of index men with at least one partner identified as infected with $C$ trachomatis was $6.2 \%$ in the home sampling group and $1.9 \%$ in the "in office" group $(p=0.02)$, a relative effectiveness of $3.3(6.2 \% / 1.9 \%)(95 \% \mathrm{CI}$ : 1.2 to 9.0$)$.

\section{Efficacy of partner testing}

Table 4 shows the proportion who had at least one partner tested when the population was restricted to only index men and women who were actually recruited to the study.

\section{DISCUSSION}

More partners exposed to $C$ trachomatis infection are tested and more infections are detected when partners are given the opportunity of home sampling compared with office sampling. Based on data from a previous study, $95 \%$ of the infected partners received treatment. ${ }^{16}$
The major limitation of our study is the rather high proportion of randomised individuals who did not submit questionnaires to the study centre and kits to their partners. We consider that many general practitioners did not provide information about the study as they were not paid or given any incentives for this extra work with the index case. The proportion of recruited men and women were higher in the home sampling group. Although the partner kits were blinded, it could, however, not be excluded that the index patients opened the partner package before they decided to forward it to their partners. Furthermore, partners might have been tested outside the study. We know that contact slips are often not brought by partners when they come for testing but partners in the office sampling group were requested to bring the specimen collection kit that allowed non-invasive testing, which otherwise would not have been the case.

The prevalence of $C$ trachomatis infection in partners to infected patients varies between 27-68\%. ${ }^{17} 2021$ Treating the partners through patient delivered therapy rather than testing the partners first could therefore seem reasonable. ${ }^{22}{ }^{23}$ However, if the partner has a positive test, he could serve as a new index case from where a new partner tracing activity can begin. In particular, this is important when treating patients in sexual networks with no regular partner. According to this, patient delivered therapy has been shown to be of highest efficacy in index patients with regular partners. ${ }^{24}$ Schillinger et $a l^{25}$ conducted a comparative study assessing reinfection rates after 4 months in index women assigned to patient referral or patient delivered therapy. The two groups had a reinfection rate of $15 \%$ and $12 \%$, respectively. The modest absolute reduction of $3 \%$ might be explained by the fact that although patient delivered therapy is well accepted ${ }^{23}$ sexual activity may be more complex and not restricted to one partner only. In fact multi-partnership has increased in the United Kingdom over the past 10 years. ${ }^{26}$ From a public health point of view, in which a reduction of disease prevalence is warranted, we therefore argue that testing first is important in order to identify new index cases. In this study we have shown that the test rate can be increased twofold to fourfold by offering partners home sampling in stead of office sampling.

Assessing only index patients who actually took part in the study (recruited index patients), $41 \%$ of index women and $13 \%$ of index men had at least one partner tested. This corresponds well with the partner notification rates found in other studies. ${ }^{13}$ The partner notification rates were increased by home sampling, but the rates might have been even higher if we had used provider referral instead of self referral. This is 
Table 2 Reasons for dropping out among index patients

\begin{tabular}{|c|c|c|c|c|}
\hline \multirow[b]{2}{*}{ Reasons } & \multicolumn{2}{|c|}{ Women } & \multicolumn{2}{|c|}{ Men } \\
\hline & No & $\%$ & No & $\%$ \\
\hline $\begin{array}{l}\text { My partner(s) is/are already aware of a } C \text { trachomatis infection } \\
\text { and has/have taken action regarding diagnosis and treatment } \\
\text { outside this study }\end{array}$ & 36 & 30.5 & 20 & 32.8 \\
\hline I found it unpleasant to contact my partner(s) & 19 & 16.1 & 9 & 14.8 \\
\hline Unknown identity of partner(s) & 12 & 10.2 & 6 & 9.8 \\
\hline The study interferes too much with privacy/personal integrity & 11 & 9.3 & 5 & 8.2 \\
\hline Participation too complicated and time consuming & 7 & 5.9 & 6 & 9.8 \\
\hline No partner(s) through the past 12 months & 3 & 2.5 & 1 & 1.6 \\
\hline No particular reason stated & 30 & 25.4 & 14 & 23.0 \\
\hline Total & 118 & 100 & 61 & 100 \\
\hline
\end{tabular}

Table 3 Effectiveness of office sampling and home sampling for testing of partners. Calculations based on the "intention to test" population

\begin{tabular}{|c|c|c|c|c|c|c|}
\hline & \multicolumn{3}{|l|}{ Index women } & \multicolumn{3}{|l|}{ Index men } \\
\hline & $\begin{array}{l}\text { Office sampling } \\
\text { ( } n=663 \text { ) }\end{array}$ & $\begin{array}{l}\text { Home sampling } \\
(n=637)\end{array}$ & $\begin{array}{l}\text { p Value } \\
\text { Effectiveness } \\
\text { difference }(95 \% \mathrm{Cl})\end{array}$ & $\begin{array}{l}\text { Office sampling } \\
(n=269)\end{array}$ & $\begin{array}{l}\text { Home sampling } \\
(n=257)\end{array}$ & $\begin{array}{l}\text { p Value } \\
\text { Effectiveness } \\
\text { difference }(95 \% \mathrm{Cl})\end{array}$ \\
\hline $\begin{array}{l}\text { No of index cases with } \\
\text { one or more partner(s) tested }\end{array}$ & 78 & 166 & $p<0.0001$ & 9 & 38 & $p<0.0001$ \\
\hline Proportion of identified cases & $11.8 \%$ & $26.1 \%$ & $14.3 \%(10.1$ to 18.5$)$ & $3.3 \%$ & $14.8 \%$ & $11.5 \%(6.7$ to 16.3$)$ \\
\hline $\begin{array}{l}\text { No of index cases with } \\
\text { one or more partner(s) infected }\end{array}$ & 44 & 69 & $p=0.01$ & 5 & 16 & $p=0.02$ \\
\hline Proportion of identified cases & $6.6 \%$ & $10.8 \%$ & $4.2 \%(1.1$ to 7.3$)$ & $1.9 \%$ & $6.2 \%$ & $4.3 \%(0.9$ to 7.7$)$ \\
\hline $\begin{array}{l}\text { Average number of tested } \\
\text { partner(s) per index patient }\end{array}$ & 0.14 & 0.31 & $p<0.0001$ & 0.04 & 0.16 & $p<0.0001$ \\
\hline
\end{tabular}

so because Katz et al ${ }^{12}$ found that provider referral instead of self referral increased the effectiveness from 0.18 to 0.72 notifications per index patient. It might therefore be reasonable to speculate that a combination of home sampling and provider referral would be beneficial. This needs to be addressed in subsequent studies.

\section{ACKNOWLEDGEMENTS}

In addition to the authors, the following investigators participated in the Chlamydia Home Sampling Partner Testing Study Group: Dr Merete Stubkjær, Department of Clinical Microbiology, Aarhus, Denmark; Henrik Laursen, Department of Clinical Microbiology, Aarhus, Denmark; and Ineta Sokolowski, Research Unit for General Practice, Aarhus University.

\section{CONTRIBUTORS}

LØ contributed to study design, study logistics, data analyses and wrote the paper; BA and FO contributed to study design, clinical coordination, data analyses and edited the paper; JKM contributed to study design, clinical coordination, data collection, data storage, data analyses and edited the paper; AW contributed to study design, clinical coordination, data collection, data analyses, and edited the paper.

Table 4 The proportion of recruited index men and index women who had at least one partner tested

\begin{tabular}{lll}
\hline & $\begin{array}{l}\text { Office sampling } \\
\text { of partners }\end{array}$ & $\begin{array}{l}\text { Home sampling } \\
\text { of partners }\end{array}$ \\
\hline $\begin{array}{l}\text { Participating index women } \\
\text { Participating Index men }\end{array}$ & $41 \%(78 / 191)$ & $\begin{array}{l}74 \%(166 / 223) \\
13 \%(67)\end{array}$ \\
\hline
\end{tabular}

\section{Authors' affiliations}

L Østergaard, B Andersen, Research Unit Q, Department of Infectious Diseases, Aarhus University Hospital, Skejby Sygehus, 8200 Aarhus N, Denmark

B Andersen, F Olesen, Research Unit and Department of General Practice, University of Aarhus, 8000 Aarhus C, Denmark

J K Møller, Department of Clinical Microbiology, Aarhus University Hospital, 8000 Aarhus C, Denmark

A-M Worm, Department of Dermato-Venerology, Bispebjerg Hospital, 2400 Copenhagen NV, Denmark

Funding: The study was supported by grants from the Danish National Board of Health, Danish Medical Research Council, Danish Centre for Evaluation and Health Technology Assessment (DACEHTA), Aage Bang's Fund, Helga og Peter Kornings Fond, and Pfizer Denmark A/S.

Competing interests: None.

\section{REFERENCES}

1 Fenton KA, Korovessis C, Johnson AM, et al. Sexual behaviour in Britain: reported sexually transmitted infections and prevalent genital Chlamydia trachomatis infection Lancet 2001:358:1851-4.

2 Andersen B, Olesen F, Møller JK, et al. Population-based strategies for outreach screening of urogenital Chlamydia trachomatis infections: a randomized, controlled trial. J Infect Dis 2002;185:252-8.

3 Klausner JD, McFarland W, Bolan G, et al. Knock-knock: a population-based survey of risk behavior, health care access, and Chlamydia trachomatis infection among low-income women in the San Francisco Bay area. J Infect Dis $2001 ; 183: 1087-92$.

4 Turner CF, Rogers SM, Miller HG et al. Untreated gonococcal and chlamydial infection in a probability sample of adults. JAMA 2002;287:726-33.

5 Hillis SD, Joesoef R, Marchbanks PA, et al. Delayed care of pelvic inflammatory disease as a risk factor for impaired fertility. Am J Obstet Gynecol 1993:168:1503-9.

6 Schachter J. Chlamydial infections. West J Med 1990;153:523-34.

7 Martin DH, Mroczkowski TF, Dalu ZA, et al. A controlled trial of a single dose of azithromycin for the treatment of chlamydial urethritis and cervicitis. The Azithromycin for Chlamydial Infections Study Group. N Engl J Med 1992;327:921-5. 
8 Scholes D, Stergachis A, Heidrich FE, et al. Prevention of pelvic inflammatory disease by screening for cervical chlamydial infection. $N$ Engl J Med 1996;334:1362-6.

9 Østergaard L, Andersen B, Møller JK, et al. Home sampling versus conventional swab sampling for screening of Chlamydia trachomatis in women: a cluster-randomized 1-year follow-up study. Clin Infect Dis 2000;31:951-7

10 Macke BA, Maher JE. Partner notification in the United States: an evidencebased review. Am J Prev Med 1999;17:230-42.

11 Katz BP, Caine VA, Jones RB. Evaluation of field follow-up in a sexually transmitted disease clinic for patients at risk for infection with Neisseria gonorrhoeae and Chlamydia trachomatis. Sex Transm Dis 1992;19:99-104

12 Katz BP. Efficiency and cost-effectiveness of field follow-up for patients with Chlamydia trachomatis infection in a sexually transmitted diseases clinic. Sex Transm Dis 1988;15:11-6.

13 Oh MK, Boker JR, Genuardi FJ, et al. Sexual contact tracing outcome in adolescent chlamydial and gonococcal cervicitis cases. J Adolesc Health 1996; 18:4-9.

14 Østergaard L. Diagnosis of urogenital Chlamydia trachomatis infection by use of DNA amplification. APMIS 1999;89(Suppl):5-36.

15 Østergaard L, Møller JK, Andersen B, et al. Diagnosis of urogenital Chlamydia trachomatis infection in women based on mailed samples obtained at home: multipractice comparative study. BMJ 1996;313:1186-9.

16 Østergaard L, Andersen B, Olesen F, et al. Efficacy of home sampling for screening of Chlamydia trachomatis: randomised study. BMJ 1998;317:26-7.

17 Andersen B, Østergaard L, Møller JK, et al. Home sampling versus conventional contact tracing for detecting Chlamydia trachomatis infection in male partners of infected women: randomised study. BMJ 1998;316:350-1.

18 Østergaard U, Andersen BS, Olesen F, et al. Detection of Chlamydia trachomatis infection among young people. The effect of home-sampling and mailing the samples. Ugeskr Laeger 1999;161:4514-8.

19 Dupont WD, Plummer WD Jr. Power and sample size calculations. A review and computer program. Control Clin Trials 1990;11:116-28.

20 Quinn TC, Gaydos C, Shepherd M, et al. Epidemiologic and microbiologic correlates of Chlamydia trachomatis infection in sexual partnerships. JAMA 1996;276: 1737-42

21 Worm AM. Transmission of chlamydial infections to sexual partners. Genitourin Med 1987;63:19-21.

22 Kissinger P, Brown R, Reed K, et al. Effectiveness of patient delivered partner medication for preventing recurrent Chlamydia trachomatis. Sex Transm Infect 1998:74:331-3

23 Golden MR, Whittington WL, Handsfield HH, et al. Partner management for gonococcal and chlamydial infection: expansion of public health services to the private sector and expedited sex partner treatment through a partnership with commercial pharmacies. Sex Transm Dis 2001 28:658-65.

24 Ramstedt K, Forssman L, Johannisson G. Contact Traceing in the Controll of Genital Chlamydia trachomatis Infection. Int J STD AIDS 1991;2:116-18.

25 Schillinger JA, Kissinger $\mathrm{P}$, Calvet $\mathrm{H}$, et al. Patient-delivered partner treatment with azithromycin to prevent repeated Chlamydia trachomatis infection among women: a randomized, controlled trial. Sex Transm Dis 2003;30:49-56.

26 Johnson AM, Mercer CH, Erens B, et al. Sexual behaviour in Britain: partnerships, practices, and HIV risk behaviours. Lancet 2001;358:1835-42.

\section{$\mathrm{ECHO}$}

\section{Young injecting drug users have a high incidence of hepatitis C}

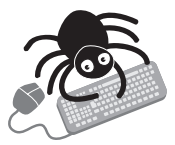

Please visit the Sexually Transmitted Infections website [www. stijournal.com] for a link to the full text of this article.

\section{$T$} he detected incidence of hepatitis C among injecting drug users in Dublin, Ireland is higher than corresponding figures from surveys in similar settings elsewhere. It contrasts with a comparatively low incidence of HIV.

Between 1992 and 1998, attenders at a drug treatment centre were encouraged to consent to testing for evidence of hepatitis $\mathrm{C}$ infection. The incidence of infection was calculated using the person years method. The date of a first negative test represented the starting point for all patients when calculating their person years at risk. The end point was the date of the last negative test if they remained seronegative or the midpoint of the last negative and first positive test for those who seroconverted.

Sixty seven of 100 patients retested seroconverted during the study period-an overall incidence of 66/100 person years (CI 51-84). A history of imprisonment was associated with a higher incidence while the group who usually smoked heroin and only occasionally injected had a lower incidence. Repeat testing for HIV in 164 patients uncovered two who seroconverted. The incidence of HIV was $0.7 / 100$ person years (CI 0.1-2.5).

The authors considered the high hepatitis $\mathrm{C}$ incidence related to the fact that the cohort was young (median age 20.5y) and were mostly recent injectors (median six months). The reason for the extra risk posed by imprisonment is unclear: it predated entry to the study so could not have been causal but might reflect a lifestyle that involves generally increased risk taking behaviour.

Strategies to halt the spread of hepatitis C need to target drug users who have recently started injecting as well and to deflect heroin smokers from moving on to injecting.

A Journal of Epidemiology and Community Health 2003;57:310-311. 